\title{
Transcatheter aortic valve replacement: Experience with the transapical approach, alternate access sites, and concomitant cardiac repairs
}

\author{
Jason Aguirre, BA, ${ }^{a}$ Robin Waskowski, BS, ${ }^{\mathrm{b}}$ Kanhaiya Poddar, MD, ${ }^{\mathrm{c}}$ Samir Kapadia, MD, ${ }^{\mathrm{d}}$ \\ Amar Krishnaswamy, MD, ${ }^{\mathrm{d}}$ Rebecca McCullough, RN, BSN, ${ }^{\mathrm{e}}$ Stephanie Mick, MD, ${ }^{\mathrm{e}}$ Jose L. Navia, MD, \\ Eric E. Roselli, MD, ${ }^{\mathrm{e}}$ Murat E. Tuzcu, MD, ${ }^{\mathrm{d}}$ Joseph F. Sabik III, MD, ${ }^{\mathrm{e}}$ Bruce W. Lytle, MD, ${ }^{\mathrm{e}}$ and \\ Lars G. Svensson, $\mathrm{MD}, \mathrm{PhD}^{\mathrm{e}}$
}

\begin{abstract}
Objectives: Transapical transcatheter aortic valve replacement (TA-TAVR) is a viable treatment option for selected high-risk elderly patients. We analyzed the 30-day mortality and perioperative complications, focusing on the "learning curve" since our first TA procedure in 2007. We also introduce unique cases, demonstrating new possibilities for alternate access sites and concurrent cardiac interventions using the apical approach.
\end{abstract}

\begin{abstract}
Methods: From February 2007 to May 2013, 150 patients underwent TA-TAVR (mean age, $81.4 \pm 7$ years; mean Society of Thoracic Surgeons score, $9.8 \pm 3.5$ ). We compared 2 groups (group A, $\mathrm{n}=65$, procedures from February 2007 to December 2010; group B, $\mathrm{n}=85$, procedures from January 2011 to May 2013).
\end{abstract}

\begin{abstract}
Results: Five deaths (3.3\%) occurred within 30 days, with a decrease in 30-day mortality between the 2 groups (group $\mathrm{A}, \mathrm{n}=4,6.2 \%$; group $\mathrm{B}, \mathrm{n}=1,1.2 \%$ ) that became significant at 1 year (log-rank, $P=.002)$. Severe bleeding from the apex (group A, 4.6\%; group B 4.4\%) and deployment of $>1$ valve (group A, $7.6 \%$; group B, $10.5 \%$ ) was similar in both groups. Valve embolization was less frequent in group B (group A, $4.6 \%$; group $\mathrm{B}, 2.4 \%)$. Postoperative complications in groups A and B included stroke $(3.1 \% \mathrm{vs} 0 \%)$, renal failure $(9.3 \%$ vs $4.7 \%)$, and permanent pacemaker implantation $(6.1 \%$ vs $5.9 \%)$. No myocardial infarctions occurred in either group. Two patients received simultaneous aortic and mitral valve implantation; 1 patient undergoing TA-TAVR also underwent distal arch and descending aorta repair; all had favorable outcomes. With a further 25 TA-TAVR since May 2013, the overall mortality is $2.9 \%(5 / 175)$.
\end{abstract}

Conclusions: Although working with the fragile apical tissues in high-risk elderly patients remains a challenge, we have demonstrated a reduction in mortality and complications with increasing experience in TA-TAVR. We have successfully demonstrated novel combined procedures and uses for the transapical approach and alternate access sites, which should continue to be explored. (J Thorac Cardiovasc Surg 2014;148:1417-22)

Aortic stenosis is a progressive disease that once symptomatic is associated with $\geq 50 \%$ mortality within 1 year of symptom onset, and many patients did not receive surgical treatment. $^{1-5}$ Transcatheter aortic valve implantation (TAVR) has emerged as a suitable alternative to conventional surgery in selected inoperable high-risk

\footnotetext{
From the Case Western Reserve University School of Medicine, ${ }^{\text {a }}$ Cleveland, Ohio; Marshall University Joan C. Edwards School of Medicine, ${ }^{\mathrm{b}}$ Huntington, WVa; and Department of Cardiovascular Medicine, ${ }^{\mathrm{c}}$ Section of Intervention, ${ }^{\mathrm{d}}$ Department of Cardiovascular Medicine, and Department of Cardiothoracic Surgery, ${ }^{\mathrm{e}}$ Heart and Vascular Institute, Cleveland Clinic, Cleveland, Ohio.

Disclosures: Eric E. Roselli reports consulting fees from Edwards, Medtronic, and DirectFlow, and equity ownership in Apica. Joseph F. Sabik reports consulting fees from Medtronic, equity ownership in Valve Exchange, and lecture fees from Medistme and Edwards. All other authors have nothing to disclose with regard to commercial support.

Received for publication Nov 29, 2013; revisions received April 21, 2014; accepted for publication May 8, 2014; available ahead of print July 1, 2014.

Address for reprints: Lars G. Svensson, MD, PhD, Department of Cardiothoracic Surgery, Heart and Vascular Institute, Cleveland Clinic, 9500 Euclid Ave, Desk J4-1, Cleveland, OH 44915 (E-mail: svenss1@ccf.org). $0022-5223 / \$ 36.00$

Copyright (C) 2014 by The American Association for Thoracic Surgery http://dx.doi.org/10.1016/j.jtcvs.2014.05.019
}

patients. It has been shown in the Placement of AoRTic TraNscathetER Valve Trial and several subsequent studies that TAVR and conventional surgery are associated with similar mortality, reduction of symptoms, and improved hemodynamics, although with an elevated stroke risk in the TAVR groups. ${ }^{5-8}$ The transfemoral approach is often the first choice for patients considered ineligible for conventional surgery, favored for being less invasive and owing to its ability to be performed completely percutaneously, at times with local anesthesia and without tracheal intubation. In certain patients with peripheral vascular disease and heavy arterial calcification transapical (TA)-TAVR has become an increasingly popular option, with outcomes comparable to transfemoral (TF)-TAVR after propensity score matching. ${ }^{9,10}$ At our institution, we have evolved our TA-TAVR technique to include simultaneous treatment of multiple cardiac pathologic entities, including percutaneous coronary intervention (PCI) and transcatheter mitral valve-in-valve implantation. ${ }^{11-13}$ We have also performed procedures using alternate access sites, such as the ascending aorta and subclavian artery. 


$$
\begin{aligned}
& \text { Abbreviations and Acronyms } \\
& \begin{aligned}
\text { CPB } & =\text { cardiopulmonary bypass } \\
\text { LV } & =\text { left ventricular } \\
\text { PCI } & =\text { percutaneous coronary intervention } \\
\text { STS } & =\text { Society of Thoracic Surgeons } \\
\text { TA } & =\text { transapical } \\
\text { TAVR } & =\text { transcatheter aortic valve implantation } \\
\text { TEE } & =\text { transesophageal echocardiography } \\
\text { TF } & =\text { transfemoral }
\end{aligned}
\end{aligned}
$$

The aim of the present study was to study our experience with TA-TAVR and explore new possibilities for alternate access sites and concomitant transcatheter repair.

\section{METHODS}

The present study was a retrospective chart review of the 150 TA-TAVR procedures performed at the Cleveland Clinic Heart and Vascular Institute from February 15, 2007 to May 29, 2013. The institutional review board approved our research study. We compared 2 groups. Group A included our first 3 years of experience with 65 patients and the procedures from February 2007 to December 2010. Group B included $>2$ years of our latest experience with 85 patients and the procedures from January 2011 to May 2013.

\section{Patient Selection}

A team of cardiac surgeons and cardiologists evaluated all patients. Ultimately, only patients considered to be inoperable or at unacceptably high risk for surgical aortic valve replacement were considered for TAVR. The patients selected for TAVR were first considered for the TF approach. Patients with tortuous vascular anatomy, poor access, or peripheral vascular disease were selected for the TA approach. Eight patients considered separately from the TA-TAVR series did not have characteristics amenable for either approach and were considered for alternate access, with 6 having the valve delivered by direct cannulation of the aorta and 2 through the left subclavian artery. These patients underwent TAVR with concomitant PCI, and 1 patient underwent simultaneous aortic and mitral valve implantation.

All patients underwent an extensive screening workup, including pulmonary function testing and transthoracic and transesophageal echocardiography (TEE). Computed tomographic angiography studies were used to study the aortic and aortic valve calcium, arterial tortuosity or calcification, aneurysm, vessel size, and degree of stenosis.

\section{Operative Technique}

All procedures were performed in sterile conditions in a hybrid fluoroscopy operating room with a team consisting of cardiac surgeons, interventional cardiologists, cardiac anesthesiologists, and echocardiographers. Other team members included perfusionists, surgical scrub nurses trained in transcatheter procedures, circulating nurses, catheterization laboratory technicians, and surgical assistants. All patients underwent surgery under general anesthesia. Fully prepared cardiopulmonary bypass (CPB) machines were present, and the femoral vessels were exposed in case of a need for CPB cannulation.

A $5 \mathrm{~F}$ femoral arterial sheath was inserted into the contralateral femoral artery. This sheath was used to insert the pigtail catheter for aortic root injections during valve positioning and for arterial cannulation in case CPB was required. A TF vein sheath was also inserted for transvenous pacemaker insertion to perform rapid ventricular pacing at balloon valvuloplasty and deployment of the Edwards SAPIEN balloon expandable valve (Edwards, Irving, Calif). An anterolateral minithoracotomy was performed in the fifth or sixth intercostal space. Pericardiotomy was performed over the left ventricular apex, and heparin was administered. Two concentric purse string sutures reinforced with pledgets and a horizontal mattress suture were placed at the left ventricular (LV) apex. The LV apex was punctured at the center of the purse string sutures using a standard access needle under TEE guidance. A soft access wire was inserted in the left ventricle through the needle and directed to the aortic valve. A $12 \mathrm{~F}$ sheath was then delivered into the LV apex. A Berman balloon-tipped wedge catheter was then floated across the aortic valve all the way to the abdominal aorta to minimize trauma to the ascending aorta and arch. A 260 -cm, 0.35-in. Amplatz extra stiff guidewire was then introduced. The $26 \mathrm{~F}$ introducer sheath was delivered over the wire through the apex. Aortic balloon valvuloplasty was performed during rapid ventricular pacing at a rate of 160 to 180 beats $/ \mathrm{min}$. The valve was then delivered through the introducer sheath and positioned across the aortic annulus.

Both TEE and aortic root angiography were used to confirm the position and orientation of the prosthetic valve. The valve was deployed in position during direct fluoroscopic visualization with rapid ventricular pacing. Respirations were also held at this time. After deployment, the prosthetic function, position, and location and the presence and degree of aortic valve regurgitation were evaluated using TEE, another angiographic root injection, and ventricular and aortic pressure recordings. Once the result had been deemed successful, the introducer sheath was removed and the purse string sutures were tied to secure hemostasis during rapid pacing. Protamine was administered, a left pleural chest tube was inserted, and the access site incision was closed.

\section{Statistical Analysis}

The categorical variables are presented as frequencies and percentages and continuous variables as the mean \pm standard deviation. The Fisher exact test was used to compare categorical variables with a value $<5$. The Pearson chi-square test was used to compare the differences between all other categorical variables. The $t$ test was used to compare the differences in the mean values for continuous variables. Log-rank analysis was used to compare the 1-year survival between the 2 groups (Figure 1).

\section{RESULTS}

\section{Preoperative Characteristics}

The baseline preoperative characteristics of all TA-TAVR patients are summarized in Table 1 . The average age of all the patients was $81.4 \pm 6.94$ years; $59.3 \%$ of the patients were male, and the average body mass index was $24.2 \pm$ $5.5 \mathrm{~kg} / \mathrm{m}^{2}$. The mean Society of Thoracic Surgeons (STS) score was $9.8 \pm 3.5$. The most common comorbidity was hypertension $(76 \%)$, followed by chronic obstructive pulmonary disease $(54.7 \%)$ and diabetes $(42 \%)$. Regarding coronary artery disease and previous revascularization, $66.7 \%$ of the patients had undergone previous coronary artery bypass grafting and $14.0 \%$ of patients had undergone previous PCI.

Preoperative echocardiography showed an average aortic valve area of $0.624 \pm 0.162 \mathrm{~cm}^{2}$, and a mean aortic gradient of $43.6 \pm 13.9 \mathrm{~mm} \mathrm{Hg}$. Finally, $14.6 \%$ of patients had an ejection fraction of $\leq 35 \%$.

\section{Intraoperative Results}

The incidence of device-related events, including the number of valves deployed, valve embolizations, valvein-valve procedures, and repeat ballooning, was not 


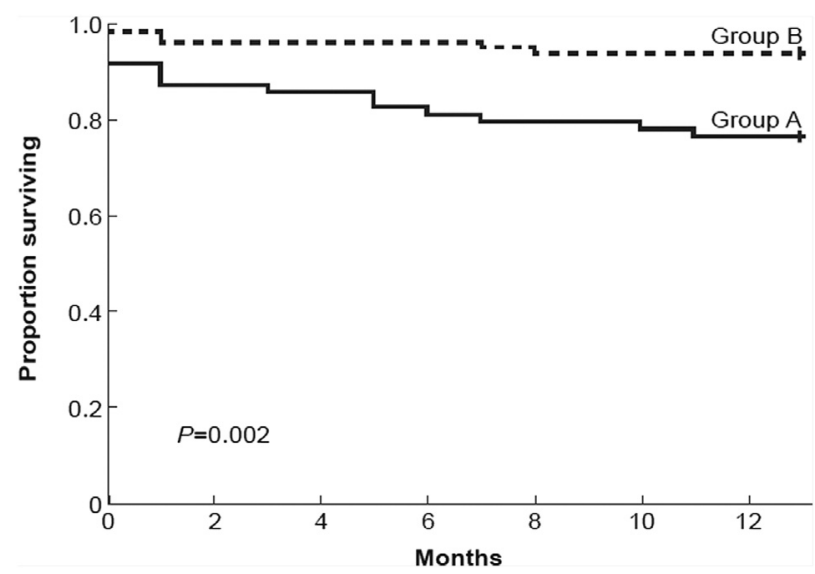

FIGURE 1. Log-rank analysis of survival $(P=.013)$.

significantly different between the 2 groups (Table 2). A total of 9 patients required a valve-in-valve in a TAVR valve, 1 of whom had 3 valves placed (valve-in-valve-in-valve). One patient had a TAVR valve placed into an old pericardial valve. In 1 patient, the TAVR valve had cracked open and another was fed into place. The incidence of valve embolization was decreased in group B $(2.4 \%$ vs $4.6 \%, P=.44)$, and the use of repeat ballooning $(14.1 \%$ vs $12.3 \%, P=.75)$ and valve-in-valve $(7.0 \%$ vs $4.6 \%, P=.53)$ were somewhat increased; however, these differences were not significant.

\section{Postoperative Results}

The postoperative course of all TA-TAVR patients is summarized in Table 2. Significantly more rescue therapies were used in group A, including more CPB $(15.4 \%$ vs $4.7 \%, P=.03)$ and an intra-aortic balloon pump $(9.2 \%$ vs $0 \%, P=.03$ ). A total of 3 neurologic events occurred, all in group $\mathrm{A}$. The incidence of new-onset atrial fibrillation was significantly less in group B $(15.3 \%$ vs $32.3 \%$, $P=.014)$; it was also the most common complication.

The incidence of other postoperative complications was similar between the 2 groups. Prolonged endotracheal intubation was the second most common complication and was moderately decreased in group $\mathrm{B}(8.2 \%$ vs $15.4 \%, P=.17)$. Of all the patients, $4.7 \%$ required reoperation for bleeding, with a similar incidence between groups A and B $(4.6 \%$ vs $4.4 \%, P=.65)$. The incidence of other complications was decreased in group $\mathrm{B}$, but the differences did not reach statistical significance. The postoperative requirement for dialysis was the only complication that was increased in group B compared with that in group A $(4.7 \%$ vs $3.1 \%$, $P=.47)$; the difference was not statistically significant.

For all patients undergoing TA-TAVR, the total 30-day mortality was $3.3 \%$. The 30 -day mortality was markedly decreased in group B compared with that in group A, but the difference did not reach statistical significance ( 1 in group B $[1.2 \%]$ vs 4 in group A $[6.2 \%] ; P=.11$ ). The total 1 -year mortality for all patients was $10 \%$. We also noted a significant decrease in 1-year mortality between groups $\mathrm{A}$ and $\mathrm{B}(16.9 \%$ vs $4.7 \%, P=.002$, log-rank test $)$.

The echocardiographic data, including central and perivalvular regurgitation and the peak and mean gradients at discharge and follow-up, are presented in Table 3 and Figure 2, respectively.

Eight patients considered separately from the TA-TAVR group were not ideal for TA-TAVR because of chest pathologic findings and were considered for alternate access, 6 patients through the aorta and 2 through the subclavian

TABLE 1. Baseline characteristics

\begin{tabular}{|c|c|c|c|c|}
\hline Characteristic & Overall $(n=150)$ & Group A $(n=65)$ & Group B $(\mathbf{n}=\mathbf{8 5})$ & $P$ value \\
\hline Age (y) & $81.4 \pm 6.94$ & $83.16 \pm 5.77$ & $80.1 \pm 7.465$ & .00 \\
\hline Male gender & $89(59.3)$ & $40(61.5)$ & $49(57.6)$ & .63 \\
\hline BMI $\left(\mathrm{kg} / \mathrm{m}^{2}\right)$ & $24.2 \pm 4.77$ & $26.0 \pm 4.77$ & $28.1 \pm 5.78$ & .03 \\
\hline STS score & $9.8 \pm 3.50(\mathrm{n}=100)$ & $11.07 \pm 3.01(\mathrm{n}=59)$ & $8.07 \pm 3.43$ & .00 \\
\hline Previous stroke & $38(25.3)$ & $22(33.8)$ & $16(18.7)$ & .04 \\
\hline Previous MI & $48(32.0)$ & $18(27.7)$ & $30(35.3)$ & .98 \\
\hline Previous CABG & $100(66.7)$ & $38(58.5)$ & $62(72.9)$ & .06 \\
\hline Previous PCI & $21(14.0)$ & $9(13.8)$ & $12(14.1)$ & .96 \\
\hline CAD & $92(61.3)$ & $38(58.5)$ & $54(63.5)$ & .53 \\
\hline DM & $63(42.0)$ & $22(33.8)$ & $41(48.2)$ & .08 \\
\hline Hypertension & $114(76.0)$ & $52 / 65(80.0)$ & $62 / 85(72.9)$ & .32 \\
\hline COPD & $82(54.7)$ & 38/65 (58.5) & 44/85 (51.8) & .41 \\
\hline PVD & $58(38.7)$ & $25 / 65(38.5)$ & $33 / 85(38.8)$ & .96 \\
\hline CKD & $47 / 150(31.3)$ & $17 / 65(26.2)$ & $30 / 85(35.3)$ & .23 \\
\hline $\operatorname{AVA}\left(\mathrm{cm}^{2}\right)$ & $0.624 \pm 0.162$ & $0.624 \pm 0.126$ & $0.626 \pm 0.185$ & .94 \\
\hline $\mathrm{LVEF} \leq 35 \%$ & $22(14.6)$ & $14(21.5)$ & $8(9.4)$ & .04 \\
\hline Mean aortic gradient $(\mathrm{mm} \mathrm{Hg})$ & $43.6 \pm 13.88$ & $43.3 \pm 13.84$ & $43.7 \pm 13.98$ & .85 \\
\hline
\end{tabular}

Data presented as mean \pm standard deviation or n (\%). BMI, Body mass index; STS, Society of Thoracic Surgeons; $M I$, myocardial infarction; $C A B G$, coronary artery bypass grafting; $P C I$, percutaneous coronary intervention; $C A D$, coronary artery disease; $D M$, diabetes mellitus; $C O P D$, chronic obstructive pulmonary disease; $P V D$, peripheral vascular disease; $C K D$, chronic kidney disease; $A V A$, aortic valve area; $L V E F$, left ventricular ejection fraction. 
TABLE 2. Operative details and outcomes*

\begin{tabular}{|c|c|c|c|c|}
\hline Variable & Overall $(\mathbf{n}=150)$ & Group A $(n=65)$ & Group B $(n=85)$ & $P$ value \\
\hline \multicolumn{5}{|l|}{ Intraoperative device related } \\
\hline$>1$ Valve deployed & $14(9.3)$ & $5(7.6)$ & $9(10.5)$ & .38 \\
\hline Valve embolism & $5(3.3)$ & $3(4.6)$ & $2(2.4)$ & .37 \\
\hline Valve-in-valve & $9(6.0)$ & $3(4.6)$ & $6(7.0)$ & .33 \\
\hline Valve size & $24.7 \pm 1.6$ & $24.6 \pm 1.7$ & $24.7 \pm 1.7$ & .48 \\
\hline Repeat ballooning & $20(13.3)$ & $8(12.3)$ & $12(14.1)$ & .74 \\
\hline Hospital length of stay (d) & $10.8 \pm 8.87$ & $11.3 \pm 10.24$ & $10.4 \pm 7.75$ & \\
\hline Intraoperative blood products & $39 / 139(28)$ & $16 / 54(30)$ & $23 / 85$ (27) & .74 \\
\hline $\mathrm{CPB}$ & $14(9.3)$ & $10(15.3)$ & $4(4.7)$ & .03 \\
\hline ECMO & $5(3.3)$ & $4(6.2)$ & $1(1.2)$ & .11 \\
\hline IABP & $6(4.0)$ & $6(9.2)$ & $0(0.0)$ & .01 \\
\hline CPR & $7(4.7)$ & $5(7.7)$ & $2(2.4)$ & .13 \\
\hline Reoperation for bleeding & $7(4.7)$ & $3(4.6)$ & $4(4.4)$ & .65 \\
\hline \multicolumn{5}{|l|}{ Neurologic event } \\
\hline Major & $2(1.3)$ & $2(3.1)$ & $0(0.0)$ & .19 \\
\hline Minor & $1(0.7)$ & $1(1.5)$ & $0(0.0)$ & .43 \\
\hline Renal failure & $10(6.7)$ & $6(9.3)$ & $4(4.7)$ & .22 \\
\hline Dialysis & $6(4.0)$ & $2(3)$ & $4(4.7)$ & .47 \\
\hline Pneumonia & $6(4.0)$ & $3(4.6)$ & $3(3.5)$ & .53 \\
\hline Prolonged ventilation & $17(11.3)$ & $10(15.4)$ & $7(8.2)$ & .17 \\
\hline Pleural effusion requiring drainage & $15(10.0)$ & $7(10.8)$ & $8(9.4)$ & .78 \\
\hline Venous thromboembolism & $6(4.0)$ & $3(4.6)$ & $3(3.5)$ & .53 \\
\hline Cardiac arrest & $2(1.3)$ & $1(1.5)$ & $1(1.2)$ & .68 \\
\hline Heart block & $9(6.0)$ & $5(7.7)$ & $4(4.7)$ & .34 \\
\hline New atrial fibrillation & $34(22.7)$ & $21(32.3)$ & $13(15.3)$ & .01 \\
\hline Permanent pacemaker & $9(6.0)$ & $4(6.2)$ & $5(5.9)$ & .60 \\
\hline Multisystem failure & $4(2.7)$ & $3(4.6)$ & $1(1.2)$ & .22 \\
\hline Death within $30 \mathrm{~d}$ & $5(3.3)$ & $4(6.2)$ & $1(1.2)$ & .11 \\
\hline
\end{tabular}

Data presented as n (\%) or mean \pm standard deviation. $C P B$, Cardiopulmonary bypass; $E C M O$, extracorporeal membrane oxygenation; $I A B P$, intra-aortic balloon pump; $C P R$, cardiopulmonary resuscitation. *Total for all groups as stated in the respective column head, unless otherwise noted

artery. Their mean age was $85.0 \pm 9.59$ years, and the average STS score was $16.81 \% \pm 6.87 \%$. Device implantation was successful in all the patients, and the 30-day mortality was $0 \% .^{11}$

Of the 3 patients who underwent simultaneous TAVR and PCI, the valve was implanted using the transaortic route in 2 and the TA route in 1. PCI was planned and performed before valve deployment in 1 patient and as postdeployment coronary occlusion therapy in 2 . PCI was performed using the $\mathrm{TF}$ approach in all 3 patients. This group had

TABLE 3. Central valvular and paravalvular regurgitation at discharge

\begin{tabular}{lccc}
\hline \multicolumn{1}{c}{ Variable } & $\begin{array}{c}\text { Overall } \\
(\mathbf{n = 1 4 3 )}\end{array}$ & $\begin{array}{c}\text { Group A } \\
(\mathbf{n = 6 0 )}\end{array}$ & $\begin{array}{c}\text { Group B } \\
(\mathbf{n = 8 3})\end{array}$ \\
\hline Aortic regurgitation & & & \\
$\quad$ None & $70(49)$ & $22(37)$ & $48(58)$ \\
Mild & $60(42)$ & $32(53)$ & $28(34)$ \\
$\quad$ Moderate & $13(9)$ & $6(10)$ & $7(8)$ \\
Perivalvular regurgitation & & & \\
$\quad$ None & $100(70)$ & $45(75)$ & $55(66)$ \\
Mild & $39(27)$ & $13(22)$ & $26(31)$ \\
$\quad$ Moderate & $4(3)$ & $2(3)$ & $2(2)$ \\
\hline
\end{tabular}

Data presented as $\mathrm{n}(\%)$. experienced no mortality, neurologic event, renal complications, or cardiac complications at 30 days. ${ }^{12}$

One patient, a 72-year-old woman, with native aortic and prosthetic mitral valve stenosis who had undergone simultaneous aortic and mitral valve-in-valve replacement delivered transapically who eventually developed intraabdominal necrosis and died 6 week after surgery. ${ }^{13}$

\section{DISCUSSION}

The decade after the first transcatheter implantation of a percutaneous valve by Cribier and colleagues ${ }^{14}$ saw a rapid development in the technology and technique, resulting in an evolution from TF to TA access ${ }^{15}$ and back to TF arterial access and, more recently, has begun to include simultaneous cardiac interventions and alternate access sites, such as the aorta and subclavian artery. ${ }^{11}$

The TF approach has been favored as the first choice for patients in most institutions, including our own. As we have gained experience with the TA technique, we have noted that a considerable learning curve exists, resulting in better outcomes as the surgical team became more experienced with this technically advanced procedure. ${ }^{16}$ In Europe, the TA approach has been performed more frequently, in part, 


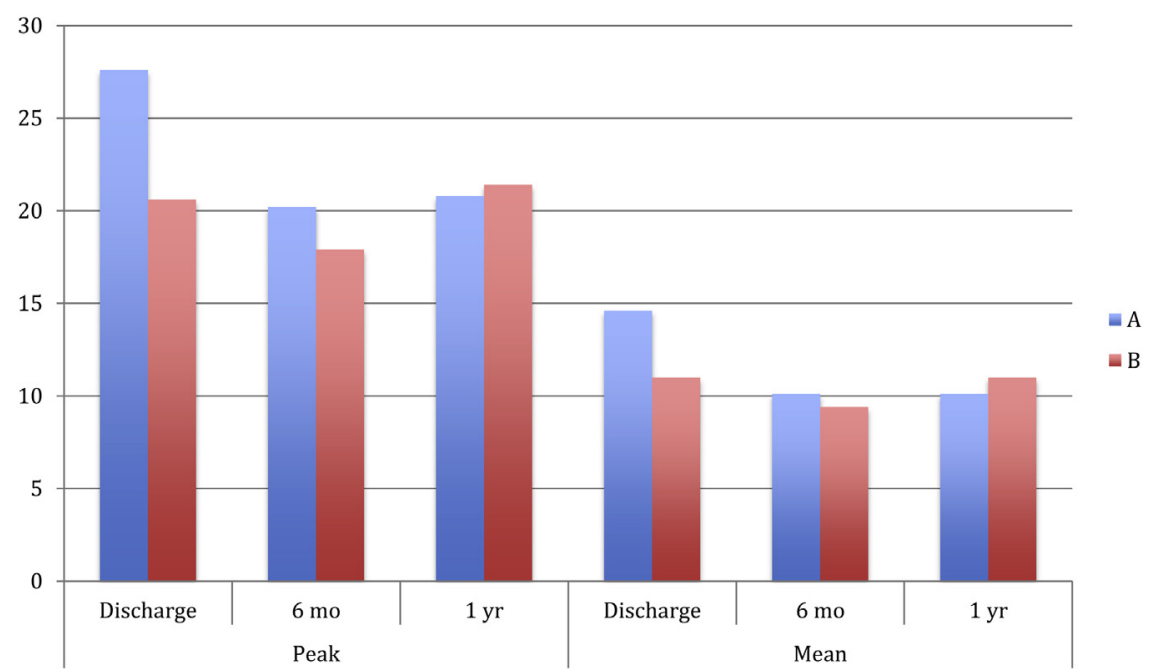

FIGURE 2. Average of A, peak and B, mean aortic valve gradients at discharge and follow-up.

because of early regulatory issues in the United States. ${ }^{15} \mathrm{~A}$ team from the United States travelled to Leipzig, Germany, for the initial research on TA-TAVR. ${ }^{15}$ Recent European studies comparing TF-TAVR and TA-TAVR showed comparable early and midterm clinical and hemodynamic outcomes between the 2 approaches. ${ }^{9,10,17}$ These findings suggest that in experienced hands, TA-TAVR is as safe and effective as TF-TAVR for the treatment for aortic stenosis. Moreover, some have suggested that an additional benefit results from the reduced fluoroscopy time, contrast use, neurologic events, and vascular complications. ${ }^{17,18}$ We have reported a decrease in both 30-day and 1-year mortality between our first 3 years of performing TA-TAVR and our latest experience. Although we observed a modest decrease in nearly all perioperative complications, the incidence of reoperation for bleeding at the apical access site was essentially unchanged (group A, $4.6 \%$ vs group B, $4.4 \% ; P=.98$ ) between the 2 groups, suggesting that the use of large bore sheaths in friable apical tissue needs to be improved. In the present study, we reported a decrease in rescue therapies, including $\mathrm{CPB}$, extracorporeal membrane oxygenation, and intra-aortic balloon pump. Also of note, was the increase in usage of valve-in-valve placement to treat primary device failure. We believe that valve-invalve is a suitable salvage therapy and might decrease the requirement for traditional rescue therapies. Valve-invalve placement has been shown to be effective in treating severe paraprosthetic leaks with unaffected hemodynamics during follow-up. ${ }^{19,20}$

Performing simultaneous repair of cardiac pathologic entities could provide the advantages of decreased cost and total hospital length of stay. Al Kindi and colleagues ${ }^{12}$ and Salhab and colleagues ${ }^{13}$ described our experience with concomitant TAVR-PCI and TAVR with combined implantation in a prosthetic mitral valve in dysfunctional mitral valve prosthesis. We have demonstrated that double aortic and mitral valve implantation is technically possible. Also, our 1 patient who died had done well in the immediate postoperative period with greatly improved hemodynamics. Furthermore, we have used both transjugular and TF venous approaches for tricuspid valve-in-valve insertion. We suggest that additional development of valves and delivery systems specifically designed for implantation into prosthetic and mitral valves will improve the feasibility of this multi-interventional procedure.

The risk factors for aortic stenosis are similar to those for atherosclerosis, and the incidence of both diseases increases with age. Thus, it is not surprising that these diseases commonly coexist in older patients, with the prevalence of coronary artery disease ranging from $25 \%$ to $50 \%$ in those with aortic stenosis; increasingly complex procedures have also been performed in the elderly with good results. $^{12,21-31}$ Our experience with 3 patients who underwent both interventions (TAVR and PCI) yielded good results with no increase in morbidity or mortality.

The future of TAVR is no longer limited to femoral or apical access sites. Al Kindi and colleagues ${ }^{11}$ reported our experience with alternative approaches, including direct cannulation of the aorta and retrograde access through the subclavian artery. These alternative approaches provided an extension of our capabilities to intervene in patients with unfavorable anatomy or requiring multiple repairs.

The main limitation of our study was that the series was relatively small with 150 patients. This made it difficult to determine with statistical significance whether the 2 groups were comparable. We have recognized that age, STS score, and ejection fraction were decreased in the later group (group B). However, we contend that these parameters do not completely account for our significant improvement in mortality. Also, the STS score does not currently account 
for all factors that preclude the use of the TF approach, including unfavorable anatomy, vascular anatomy, and severe arterial calcification. We have continued to perform TA-TAVR at our institution. Future studies with larger patient series should include an analysis of how different individual factors affect long-term survival, including postdeployment hemodynamics and other perioperative complications.

\section{CONCLUSIONS}

TA-TAVR is a technically advanced procedure with a substantial learning curve that, when performed by an experienced surgical team, can be accomplished with minimal morbidity and mortality. Concurrent transcatheter cardiac interventions using apical and alternative access sites are the new frontier of this rapidly evolving field and merit additional exploration.

\section{References}

1. Varadarajan P, Kapoor N, Bansal RC, Pai RG. Clinical profile and natural history of 453 nonsurgically managed patients with severe aortic stenosis. Ann Thorac Surg. 2006;82:2111-5.

2. Bach DS, Siao D, Girard SE, Duvernoy C, McCallister BD Jr, Gualano SK. Evaluation of patients with severe symptomatic aortic stenosis who do not undergo aortic valve replacement: the potential role of subjectively overestimated operative risk. Circ Cardiovasc Qual Outcomes. 2009;2:533-9.

3. Lung B, Baron G, Butchart EG, Delahaye F, Gohlke-Bärwolf C, Levang OW, et al. A prospective survey of patients with valvular heart disease in Europe: the Euro Heart Survey on Valvular Heart Disease. Eur Heart J. 2003;24:1231-43.

4. Bonow RO, Carabello BA, Chatterjee K, de Leon AC Jr, Faxon DP, Freed MD, et al. American College of Cardiology/American Heart Association Task Force on Practice Guidelines: 2008 focused update incorporated into the ACC/AHA 2006 guidelines for the management of patients with valvular heart disease: a report of the American College of Cardiology/American Heart Association Task Force on Practice Guidelines (Writing Committee to revise the 1998 guidelines for the management of patients with valvular heart disease). Endorsed by the Society of Cardiovascular Anesthesiologists, Society for Cardiovascular Angiography and Interventions, and Society of Thoracic Surgeons. J Am Coll Cardiol. 2008;118:887-96.

5. Reynolds MR, Magnuson EA, Lei Y, Leon MB, Smith CR, Svensson LG, et al; Placement of Aortic Transcatheter Valves (PARTNER) Investigators. Healthrelated quality of life after transcatheter aortic valve replacement in inoperable patients with severe aortic stenosis. Circulation. 2011;124:1964-7.

6. Kodali SK, Williams MR, Smith CR, Svensson LG, Webb JG, Makkar RR, et al; PARTNER Trial Investigators. Two-year outcomes after transcatheter or surgical aortic-valve replacement. $N$ Engl J Med. 2012;366:1686-95.

7. Smith CR, Leon MB, Mack MJ, Miller DC, Moses JW, Svensson LG, et al; PARTNER Trial Investigators. Transcatheter versus surgical aortic-valve replacement in high-risk patients. N Engl J Med. 2011;364:2187-98.

8. Leon MB, Smith CR, Mack M, Miller DC, Moses JW, Svensson LG, et al; PARTNER Trial Investigators. Transcatheter aortic-valve implantation for aortic stenosis in patients who cannot undergo surgery. N Engl J Med. 2010;363:1597-607.

9. D’Onofrio A, Salizzoni S, Agrifoglio M, Cota L, Luzi G, Tartara PM, et al. Medium term outcomes of transapical aortic valve implantation: results from the Italian registry of trans-apical aortic valve implantation. Ann Thorac Surg. 2013:96:830-6.

10. Johansson M, Nozohoor S, Kimblad PO, Harnek J, Olivecrona GK, Sjögren J. Transapical versus transfemoral aortic valve implantation: a comparison of survival and safety. Ann Thorac Surg. 2011;91:57-63.

11. Al Kindi AH, Salhab KF, Roselli EE, Kapadia S, Tuzcu EM, Svensson LG. Alternative access options for transcatheter aortic valve replacement in patients with no conventional access and chest pathology. J Thorac Cardiovasc Surg. 2014; 147:644-51.
12. Salhab KF, Al Kindi AH, Lane JH, Knudson KE, Kapadia S, Roselli EE, et al. Concomitant percutaneous coronary intervention and transcatheter aortic valve replacement: safe and feasible replacement alternative approaches in high-risk patients with severe aortic stenosis and coronary artery disease. J Card Surg. 2013;28:481-3.

13. Al Kindi AH, Salhab KF, Kapadia S, Roselli EE, Krishnaswamy A, Grant A, et al. Simultaneous transapical transcatheter aortic and mitral valve replacement in a high-risk patient with a previous mitral bioprosthesis. J Thorac Cardiovasc Surg. 2012;144:e90-1.

14. Cribier A, Eltchaninoff H, Bash A, Borenstein N, Tron C, Bauer F, et al. Percutaneous transcatheter implantation of an aortic valve prosthesis for calcific aortic stenosis: first human case description. Circulation. 2002;106:3006-8.

15. Svensson LG, Dewey T, Kapadia S, Roselli EE, Stewart A, Williams M, et al. United States feasibility study of transcatheter insertion of a stented aortic valve by the left ventricular apex. Ann Thorac Surg. 2008;86:46-54.

16. Kempfert J, Rastan A, Holzhey D, Linke A, Schuler G, van Linden A, et al. Transapical aortic valve implantation: analysis of risk factors and learning experience in 299 patients. Circulation. 2011;124:S124-9.

17. Ewe SH, Delgado V, Ng AC, Antoni ML, van der Kley F, Marsan NA, et al. Outcomes after transcatheter aortic valve implantation: transfemoral versus transapical approach. Ann Thorac Surg. 2011;92:1244-51.

18. Bleiziffer S, Ruge H, Mazzitelli D, Hutter A, Opitz A, Bauernschmitt R, et al. Survival after transapical and transfemoral aortic valve implantation: talking about two different patient populations. J Thorac Cardiovasc Surg. 2009;38: 1073-80.

19. Kempfert J, Girrbach F, Haensig M, Subramanian S, Holzhey DM, Mohr FW. Transapical aortic valve-in-valve-in-valve implantation as a procedural rescue option. Ann Thorac Surg. 2013;95:325-8.

20. Napodano M, Gasparetto V, Tarantini G, Fraccaro C, Yzeiraj E, Gerosa G, et al. Performance of valve-in-valve for severe para-prosthetic leaks due to inadequate transcatheter aortic valve implantation. Catheter Cardiovasc Interv. 2011;78: 996-1003.

21. Goel SS, Ige M, Tuzcu EM, Ellis SG, Stewart WJ, Svensson LG, et al. Severe aortic stenosis and coronary artery disease-implications for management in the transcatheter aortic valve replacement era: a comprehensive review. J Am Coll Cardiol. 2013;62:1-10.

22. Rapp AH, Hillis LD, Lange RA, Cigarroa JE. Prevalence of coronary artery disease in patients with aortic stenosis with and without angina pectoris. Am J Cardiol. 2001;87:1216-7.

23. Dewey TM, Bowers B, Thourani VH, Babaliaros V, Smith CR, Leon MB, et al. Transapical aortic valve replacement for severe aortic stenosis: results from the nonrandomized continued access cohort of the PARTNER trial. Ann Thorac Surg. 2013;96:2083-9.

24. Svensson LG, Adams DH, Bonow RO, Kouchoukos NT, Miller DC, O’Gara PT, et al. Aortic valve and ascending aorta guidelines for management and quality measures. Ann Thorac Surg. 2013;95(6 suppl):S1-66.

25. Mick SL, Kapadia S, Tuzcu M, Svensson LG. Transcatheter valve-in-valve tricuspid valve replacement via internal jugular and femoral approaches. J Thorac Cardiovasc Surg. 2014;147:e64-5.

26. Svensson LG, Tuzcu M, Kapadia S, Blackstone EH, Roselli EE, Gillinov AM, et al. A comprehensive review of the PARTNER trial. J Thorac Cardiovasc Surg. 2013;145(3 Suppl):S11-6.

27. Tuzcu EM, Kapadia SR, Svensson LG. Valve in valve: another milestone for transcatheter valve therapy. Circulation. 2012;126:2280-2.

28. Miller DC, Blackstone EH, Mack MJ, Svensson LG, Kodali SK, Kapadia S, et al; PARTNER Trial Investigators and Patients; PARTNER Stroke Substudy Writing Group and Executive Committee. Transcatheter (TAVR) versus surgical (AVR) aortic valve replacement: occurrence, hazard, risk factors, and consequences of neurologic events in the PARTNER trial. J Thorac Cardiovasc Surg. 2012;143: $832-43$.

29. Caceres M, Braud R, Roselli EE. The axillary/subclavian artery access route for transcatheter aortic valve replacement: a systematic review of the literature. Ann Thorac Surg. 2012;9:1013-8.

30. Beach JM, Mihaljevic T, Svensson LG, Rajeswaran J, Marwick T, Griffin B, et al. Coronary artery disease and outcomes of aortic valve replacement for severe aortic stenosis. J Am Coll Cardiol. 2013;61:837-48.

31. Beach JM, Mihaljevic T, Rajeswaran J, Marwick T, Edwards ST, Nowicki ER, et al. Ventricular hypertrophy and left atrial dilatation persist and are associated with reduced survival after valve replacement for aortic stenosis. J Thorac Cardiovasc Surg. 2014;147:362-9.e8. 